\title{
Development of Inorganic Membranes for Hydrogen Separation
}

\author{
Brian L. Bischoff \\ Oak Ridge National Laboratory, 1 Bethel Valley Road, P.O. Box 2008, Oak Ridge, TN 37831 \\ E-mail: bischoffbl@ornl.gov; Telephone: (865) 241-3172; Fax: (865) 576-3502 \\ Roddie R. Judkins \\ Oak Ridge National Laboratory, 1 Bethel Valley Road, P.O. Box 2008, Oak Ridge, TN 37831 \\ E-mail: judkinsrr@ornl.gov Telephone: (865) 574-4572; Fax: (865) 574-4357
}

\begin{abstract}
This paper presents information and data relative to recent advances in the development at Oak Ridge National Laboratory of porous inorganic membranes for high-temperature hydrogen separation. The Inorganic Membrane Technology Laboratory, which was formerly an organizational element of Bechtel Jacobs Company, LLC, was formally transferred to Oak Ridge National Laboratory on August 1, 2002, as a result of agreements reached between Bechtel Jacobs Company, the management and integration contractor at the East Tennessee Technology Park (formerly the Oak Ridge Gaseous Diffusion Plant or Oak Ridge K-25 Site); UT-Battelle, the management and operating contractor of Oak Ridge National Laboratory; and the U.S. Department of Energy (DOE) Oak Ridge Operations Office.

Research emphasis during the last year has been directed toward the development of high-permeance (high-flux) and high-separation-factor metal-supported membranes. Performance data for these membranes are presented and are compared with performance data for membranes previously produced under this program and for membranes produced by other researchers. New insights into diffusion mechanisms are included in the discussion. Fifteen products, many of which are the results of research sponsored by the DOE Fossil Energy Advanced Research Materials Program, have been declared unclassified and have been approved for commercial production.
\end{abstract}

\section{Introduction}

Inorganic membranes with pore sizes less than $1 \mathrm{~nm}$ offer many advantages over thin-film palladium membranes and ion-transport membranes for the separation of hydrogen from a mixed-gas stream. In microporous membranes, the flux is directly proportional to the pressure, whereas in palladium membranes it is proportional to the square root of the pressure. Therefore, microporous membranes become the more attractive option for systems that operate at increased pressure. An added feature of the microporous membranes is that their permeance increases dramatically with temperature. Consequently, inorganic membranes have the potential to produce very high fluxes at elevated temperatures and pressures. The membranes can be fabricated from a variety of materials (ceramics and metals) because the separation process is purely physical, not ion transport. Proper material selection can ensure that the membrane will have a long lifetime while maintaining high flux and selectivity. One further advantage is the relatively low cost of microporous membranes. Because their fabrication does not require the use of exotic materials or precious metals, such as palladium, the cost of producing microporous membranes should be low compared with that for palladium membranes.

One disadvantage of microporous inorganic membranes is that they are porous. They can never produce $100 \%$ pure gas streams as can thin-film-palladium or ion-transport membranes. However, when microporous membranes are coupled with pressure swing adsorption (PSA), the combined system can produce 100\% hydrogen. In this scenario, PSA would only be required to separate the final $1 \%$ of the impurities, and the coupling of the two technologies should result in a very compact and efficient separation system. 


\section{Membrane Fabrication}

The permeance of a homogeneous membrane is inversely proportional to the membrane thickness. To be effective for gas separations, the mean pore diameter should be $2 \mathrm{~nm}$ or less. With such small pores, the membrane must be very thin, preferably less than $2 \mu \mathrm{m}$, in order to have the highest flux at the lowest pressure drop. Such a thin membrane is too weak to support itself and it must be applied as a layer onto a strong, porous support material, either metal or ceramic. It is preferable that the separative layer be applied to the inside of the tube for its protection. Metal is preferred for the support tube for several reasons. For example, metal tubes are easier to incorporate into a module. Also, ceramic support tubes can be prone to catastrophic failure. If a tube fails, the broken pieces can result in a cascading effect, causing others to break.

The primary or separative membrane layer can be applied directly to the support tube or to an intermediate layer. A layer having an intermediate pore size applied to the support tube first can provide a better surface for the primary separative layer, resulting in a thinner and more uniform membrane. The primary layer should have a mean effective pore diameter of $10 \mathrm{~nm}$ or less and preferably as small as $2 \mathrm{~nm}$. Once the primary layer is in place, various chemical treatments can be used to reduce the effective pore diameter to the desired value (as low as 0.5 $\mathrm{nm})$.

It is extremely difficult to fabricate a membrane with absolutely no defects. Fabricated membranes are evaluated by combining measurements made on them with a model ${ }^{1}$ to estimate the percentage of flow through the defects and to estimate the amount that the separation factor would be lowered by their presence. Because a defect can allow the unimpeded flow of both the desired product gas and the undesired gases, the number of defects must be minimized in order to achieve a high separation factor. Several methods have been developed to reduce the effective pore diameter of a defect or to eliminate the defect altogether. These defect repair methods do not significantly reduce the number of small pores and thus do not lower the flux rate of hydrogen through the membrane.

\section{Membrane Characterization and Testing}

The two most important characteristics of inorganic membranes are permeance and separation factor. Permeance is a measure of the gas flow rate per unit area per unit pressure difference. A more fundamental unit is permeability, which is the permeance multiplied by the thickness of the membrane. In most cases, the thickness of the membrane is not known very accurately and so permeance is a more practical unit.

The separation factor is meaningful only with respect to a mixture of two gases. The ideal separation factor is the ratio of the permeance of the two gases measured at zero pressure, where there is no interaction or momentum exchange between them. Each gas flows through the membrane as if the other gas were not there. The ideal separation factor for a given temperature can be estimated by measuring the permeance of each gas separately as a function of average pressure and extrapolating the permeance to zero average pressure. The ideal separation factor is then the ratio of the zero-pressure permeances.

The transport of gases through membranes behaves differently as the pore diameter is reduced. Gas transport can also be affected by temperature, and a change in temperature can affect diffusion differently at different pore diameters. However, measuring pore diameters that are smaller than $2 \mathrm{~nm}$ is extremely difficult. Therefore, it is critically important to be able to follow the changes in the transport mechanisms of different gases during porediameter reduction to help determine the extent to which pores have been reduced. A detailed protocol is followed to help follow the changes in transport mechanisms. 
Several theoretically based models have been developed to help understand the transport mechanisms. One of the most important is the Hard Sphere Model, ${ }^{2,3}$ which combines the effect of the size of the gas molecule with Knudsen diffusion. Separation by Knudsen diffusion generally treats gas molecules as points having no molecular dimensions. In reality, the diameter of a pore appears to the molecule to be the pore diameter minus its own diameter (or its equivalent hard sphere). Without taking into account the molecular diameter, the separation factor for free molecule diffusion (Knudsen flow) is the square root of the molecular weight ratio. With the molecular diameter consideration, the separation factor for free molecule diffusion (Knudsen flow) is the square root of the molecular weight ratio (Knudsen separation factor) multiplied by the cube of the ratio of the difference between the pore diameter and the molecular diameter for each molecule. The effects that the molecular diameter and molecular size have on the theoretical separation factor are demonstrated in Figure 1 with several gas pairs. This model provides a mathematical formula for what is essentially a bridge between the Knudsen separation factor and the molecular sieve separation factor. When the pore diameter becomes equal to or less than the larger of the two molecules, the larger molecule cannot pass through the membrane and the separation factor becomes infinite (as in a molecular sieve). As can be seen in Figure 1, the larger the difference in the molecular diameters, the larger the pore diameter can be where the separation factor becomes infinite, as is the case with hydrogen/ $\mathrm{CF}_{4}$ and helium $/ \mathrm{CF}_{4}$. The effective hard sphere diameters, in angstroms, of the molecules used in the calculations for Figure 1, are as follows: helium 2.58, hydrogen 2.97, nitrogen 3.68, carbon dioxide 3.99, carbon tetrafluoride 4.7, and sulfur dioxide 4.11. The information in Figure 1 clearly shows that there is a potential for achieving very large separation factors, even at pore diameters larger than the molecular sieve pore diameter, when there is a difference in the molecular diameters of the gas pair.

Free molecule diffusion is not the only transport mechanism. The next most important transport mechanism is surface flow. Surface flow occurs when there is significant adsorption of a gas on the walls of the membrane. While the molecules are adsorbed on the membrane surfaces, they are in motion and can diffuse along the surface. In general, the heavier the molecule or the larger the interaction potential between the membrane surface and the molecule, the larger the adsorption and the more surface flow occurs. Since this transport mechanism favors the heavier molecule, it tends to decrease the separation factor. Surface flow has been included in the full mathematical transport model. ${ }^{3}$ However, adsorption and surface flow measurements are required to evaluate constants in the mathematical formulation. To date, these measurements have only been completed for carbon dioxide and an alumina membrane at $25^{\circ} \mathrm{C}$. Model calculations were then made for the binary pair (helium and carbon dioxide). Zero surface flow for helium was assumed. The results of these calculations are shown in Figure 2. As the pore diameter decreases, the gas-phase diffusion decreases and the surface flow increases, primarily because the amount of surface area increases relative to the pore volume. This decrease in flow causes the separation factor to decrease until the pore diameter approaches the diameter of carbon dioxide, at which point the transport of the carbon dioxide decreases sharply while the separation factor increases sharply. The calculation was based on the flow of the individual pure gases. It does not take into account the fact that adsorbed carbon dioxide molecules may decrease the effective size of the pore diameter and may thus impede the flow of the helium molecules. Therefore, in a mixed-gas separation, the separation factor may be even smaller than is shown in Figure 2. It should be pointed out that the separation factor drops below unity and becomes less than one under certain conditions, which means that the carbon dioxide permeance is larger than the helium permeance. 


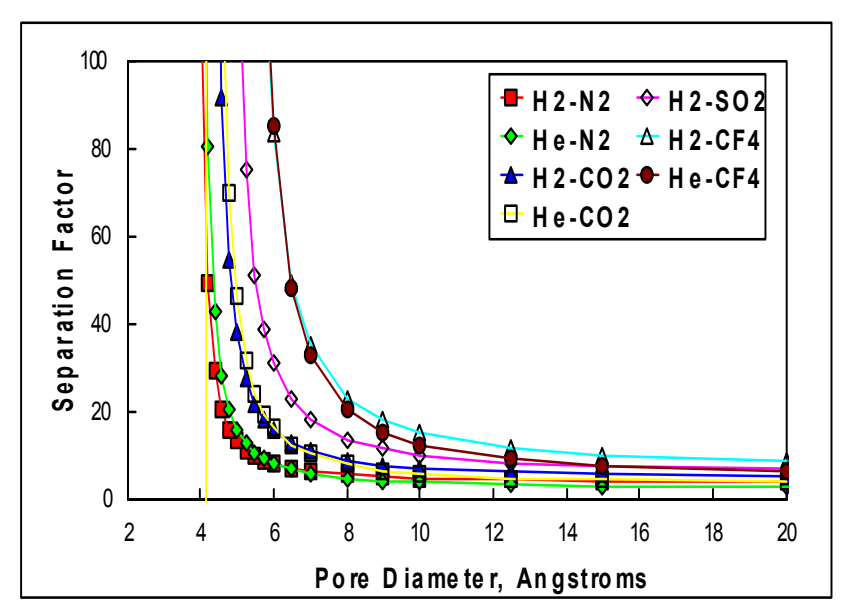

Figure 1 Separation factors for gas pairs with different relative sizes as a function of pore diameter obtained by using the Hard Sphere Transport Model.

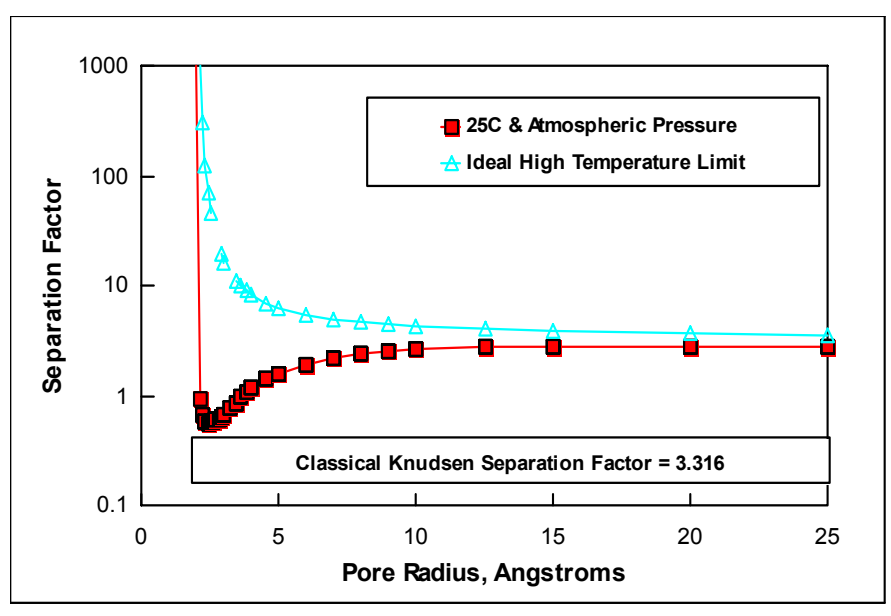

Figure $2 \mathrm{He}-\mathrm{CO}_{2}$ separation factors at $25^{\circ} \mathrm{C}$ calculated from the Full Transport Model compared with the Hard Sphere Free Molecule Diffusion Model.

\section{Permeance Measurements}

Rapid and highly accurate permeance measurements are the heart and soul of our membrane development management protocol. Single-point permeance measurements are of little value. Permeance is measured as a function of average pressure. A linear regression of permeance vs average pressure provides valuable information (we use the sum of the feed pressure and permeate pressure, which is twice the average pressure, and refer to it as $\Sigma \mathrm{P}$ or pressure summation). Initial testing is performed with air at room temperature. A series of 5 to 25 permeance measurements is made over an average pressure range from about 50 to $200 \mathrm{~cm} \mathrm{Hg}$. A linear regression is calculated, and then calculations are made of zero permeance, a permeance deviation factor, and the permeance at an average pressure of $75 \mathrm{~cm} \mathrm{Hg}$. The permeance deviation factor is the ratio of the slope of the linear regression to the zero-pressure permeance. A positive value may indicate viscous flow from defects in the membrane. These measurements are made on the membrane at every stage of development.

Membranes that show promise, by having a small permeance deviation factor, go to the next level of permeance testing, where permeance measurements are made over the same average pressure range but at more than one temperature, typically 25,150 , and $250^{\circ} \mathrm{C}$. This series of measurements is made with three or four pure gases selected from helium, hydrogen, oxygen, argon, carbon dioxide, carbon tetrafluoride, and sulfur hexafluoride. A linear regression with pressure summation (sum of feed and permeate pressure) is made at each temperature and for each gas. The ideal separation factor for each gas with respect to helium is calculated from the zero-pressure permeances. The ideal separation factor is extrapolated to $1 / \mathrm{T}=0$. At infinite temperature $(1 / \mathrm{T}=0)$, no adsorption would be expected. Therefore, the flow is primarily free molecule diffusion. The equation used to calculate the results in Figure 1 can be used with the ideal separation factor at $1 / T=0$ and the molecular diameters to calculate a mean pore diameter for the membrane. While the accuracy of this pore diameter calculation is unknown, it does provide a parameter to track the progress in reducing the membrane pore diameter. 


\section{Results}

Helium has been found to behave similarly to hydrogen in microporous membranes and is much safer to use in the laboratory. Therefore, most of our preliminary testing has employed helium as a surrogate for hydrogen. Because much of our testing is completed at temperatures less than $250^{\circ} \mathrm{C}$ and because sulfur hexafluoride is more inert than most hydrocarbons or carbon dioxide, sulfur hexafluoride is often employed to simulate larger hydrocarbons that may be present in a gas stream.

Only the membranes that showed promise (i.e. small permeance deviation factor) in the testing with air at room temperature were subject to testing with multiple gases at higher temperatures. Results of selected membranes from recent membrane development work are presented in Tables 1, 2, and 3. Table 1 lists the permeance of helium, oxygen, carbon dioxide, and sulfur hexafluoride at two temperatures. The data is listed in reverse chronological order with the most recent work at the top of table and the data at the bottom of the table being from early in 2002. Ideal separation factors were calculated from the data for each of the gas pairs $\left(\mathrm{He} / \mathrm{O}_{2}\right.$, $\mathrm{He} / \mathrm{CO}_{2}$, and $\mathrm{He} / \mathrm{SF}_{6}$ ) at both temperatures and are presented in Table 2. Of special note is how much better the most recent membranes perform. Recent membranes were found to have ideal separation factors of helium from sulfur hexafluoride over 30 at room temperature and over 100 at $250^{\circ} \mathrm{C}$. Work earlier in the year resulted in $\mathrm{He} / \mathrm{SF}_{6}$ separation factors mostly in the single digits and often less than would be expected from Knudsen diffusion. The large improvement in the separation factor is believed to be attributable to a recent improvement in the process to eliminate defects. For ideal free molecule diffusion, the ratios of the permeances predict Knudsen separation factors of 3.316 for $\mathrm{He} / \mathrm{CO}_{2}, 2.827$ for $\mathrm{He} / \mathrm{O}_{2}$, and 6.041 for $\mathrm{He} / \mathrm{SF}_{6}$. An ideal separation factor greater than this indicates a higher-than-expected separation factor than would be predicted if Knudsen diffusion alone were the mechanism governing gas flow through these fine pores.

Table 1 also shows how the permeance consistently increased as the temperature increased for all gases except the carbon dioxide. Depending on the membrane, the permeance of carbon dioxide sometimes increased and sometimes decreased with increasing temperature. This is believed to be a function of the amount of surface flow occurring along the walls of the pores at room temperature. An increase in permeance with temperature is contrary to what would be predicted if transport were governed by Knudsen diffusion. This phenomenon is believed to be caused by a thermally activated diffusion process that is not well understood at this time. One interesting feature of this mechanism is that it does not seem to affect all gases in the same way. With the most recent membranes (e.g., 2528b and 5021b), the permeance of helium increased by a factor of between five and six when the temperature was increased to $250^{\circ} \mathrm{C}$ while the permeance of sulfur hexafluoride only increased by a factor of less than two. It may be possible to take advantage of this phenomenon, which only appears to occur in very fine pores (or at least is much more pronounced in fine pores). Adjustment of the temperature may result in both an increase in hydrogen flux rate and an increase in the separation factor.

The separation factors extrapolated to $1 / \mathrm{T}=0$ and the Hard Sphere Model were used to calculate pore diameter (see Table 3). It is clear from the results that the Hard Sphere Model does not always accurately describe the transport of molecules through these small pores. The model does not incorporate surface diffusion, nor does it account for the increase in permeance that was found when the temperature was increased. More work will be needed to better understand these mechanisms so that they can be incorporated into an expanded, more comprehensive predictive model. 
Table 1. Permeance data of three gases for a series of membranes at room temperature at and $250^{\circ} \mathrm{C}$ $\left(\mathrm{scm}^{3} / \mathrm{cm}^{2} \cdot \mathrm{s} \cdot \mathrm{cm} \mathrm{Hg}\right)$

\begin{tabular}{|c|c|c|c|c|c|c|c|c|}
\hline \multirow[b]{2}{*}{ Tube } & \multicolumn{2}{|c|}{ He Permeance } & \multicolumn{2}{|c|}{$\mathrm{O}_{2}$ Permeance } & \multicolumn{2}{|c|}{$\mathrm{CO}_{2}$ Permeance } & \multicolumn{2}{|c|}{$\mathrm{SF}_{6}$ Permeance } \\
\hline & $23^{\circ} \mathrm{C}$ & $250{ }^{\circ} \mathrm{C}$ & $23^{\circ} \mathrm{C}$ & $250{ }^{\circ} \mathrm{C}$ & $23^{\circ} \mathrm{C}$ & $250^{\circ} \mathrm{C}$ & $23^{\circ} \mathrm{C}$ & $250{ }^{\circ} \mathrm{C}$ \\
\hline$\overline{25227 a}$ & $6.71 \mathrm{e}-04$ & $3.20 \mathrm{e}-03$ & $2.48 \mathrm{e}-04$ & $6.56 \mathrm{e}-04$ & $9.42 \mathrm{e}-04$ & $1.04 \mathrm{e}-03$ & $6.58 \mathrm{e}-05$ & $7.77 \mathrm{e}-05$ \\
\hline $2528 b$ & $8.77 e-04$ & $5.03 e-03$ & $2.79 \mathrm{e}-04$ & $1.16 \mathrm{e}-03$ & $1.20 \mathrm{e}-03$ & $1.76 \mathrm{e}-03$ & $1.86 \mathrm{e}-05$ & $3.65 \mathrm{e}-05$ \\
\hline $5021 b$ & $5.93 \mathrm{e}-04$ & $3.22 \mathrm{e}-03$ & $2.67 \mathrm{e}-04$ & $8.27 \mathrm{e}-04$ & $1.86 \mathrm{e}-03$ & $1.28 \mathrm{e}-03$ & $1.66 \mathrm{e}-05$ & $2.39 \mathrm{e}-05$ \\
\hline $5022 \mathrm{a}$ & $1.67 \mathrm{e}-03$ & $5.71 \mathrm{e}-03$ & $1.19 \mathrm{e}-03$ & $1.83 \mathrm{e}-03$ & $6.77 \mathrm{e}-03$ & $2.88 \mathrm{e}-03$ & $1.26 \mathrm{e}-04$ & $1.32 \mathrm{e}-04$ \\
\hline $2527 b$ & $5.30 \mathrm{e}-04$ & $3.36 \mathrm{e}-03$ & $1.24 \mathrm{e}-04$ & $6.46 \mathrm{e}-04$ & $5.29 \mathrm{e}-04$ & $9.35 \mathrm{e}-04$ & $2.86 \mathrm{e}-05$ & $3.93 e-05$ \\
\hline $2527 \mathrm{a}$ & $1.22 \mathrm{e}-03$ & $4.36 \mathrm{e}-03$ & $6.00 \mathrm{e}-04$ & $1.04 \mathrm{e}-03$ & $2.78 \mathrm{e}-03$ & $1.54 \mathrm{e}-03$ & $7.29 \mathrm{e}-05$ & $8.85 \mathrm{e}-05$ \\
\hline $5021 \mathrm{a}$ & $1.59 \mathrm{e}-03$ & $4.44 \mathrm{e}-03$ & $1.10 \mathrm{e}-03$ & $1.40 \mathrm{e}-03$ & $5.43 e-03$ & $2.14 \mathrm{e}-03$ & $2.42 \mathrm{e}-04$ & $1.57 \mathrm{e}-04$ \\
\hline $25221 \mathrm{a}$ & $5.11 \mathrm{e}-04$ & $2.96 \mathrm{e}-03$ & $2.79 \mathrm{e}-04$ & $6.86 \mathrm{e}-04$ & $1.41 \mathrm{e}-03$ & $1.06 \mathrm{e}-03$ & $7.27 \mathrm{e}-05$ & $5.61 \mathrm{e}-05$ \\
\hline $25210 \mathrm{a}$ & $1.56 \mathrm{e}-03$ & $4.62 \mathrm{e}-03$ & $8.72 \mathrm{e}-04$ & $1.23 \mathrm{e}-03$ & $4.57 \mathrm{e}-03$ & $1.82 \mathrm{e}-03$ & $8.35 \mathrm{e}-05$ & $1.17 \mathrm{e}-04$ \\
\hline $2525 \mathrm{a}$ & $1.93 \mathrm{e}-03$ & $5.79 \mathrm{e}-03$ & $1.89 \mathrm{e}-03$ & $1.86 \mathrm{e}-03$ & $1.04 \mathrm{e}-02$ & $2.85 \mathrm{e}-03$ & $1.67 \mathrm{e}-04$ & $9.47 \mathrm{e}-05$ \\
\hline $108 \mathrm{~b}$ & $2.46 \mathrm{e}-04$ & $6.51 \mathrm{e}-04$ & $8.37 \mathrm{e}-05$ & $1.06 \mathrm{e}-04$ & $7.50 \mathrm{e}-05$ & $9.61 \mathrm{e}-05$ & $4.35 \mathrm{e}-05$ & $5.01 \mathrm{e}-05$ \\
\hline $60 \mathrm{~b}$ & $4.06 \mathrm{e}-04$ & $4.10 \mathrm{e}-04$ & $1.54 \mathrm{e}-04$ & $1.45 \mathrm{e}-04$ & $1.49 \mathrm{e}-04$ & $1.24 \mathrm{e}-04$ & $9.47 \mathrm{e}-05$ & $7.15 \mathrm{e}-05$ \\
\hline $106 \mathrm{a}$ & $1.24 \mathrm{e}-03$ & $2.49 \mathrm{e}-03$ & $1.09 \mathrm{e}-03$ & $1.79 \mathrm{e}-03$ & $1.96 \mathrm{e}-03$ & $2.14 \mathrm{e}-03$ & $7.96 \mathrm{e}-04$ & $8.76 \mathrm{e}-04$ \\
\hline $108 \mathrm{a}$ & $1.15 \mathrm{e}-03$ & $3.19 \mathrm{e}-03$ & $4.55 \mathrm{e}-04$ & $7.65 e-04$ & $6.46 \mathrm{e}-04$ & $7.83 e-04$ & $2.94 \mathrm{e}-04$ & $3.05 \mathrm{e}-04$ \\
\hline $5426 a$ & $4.52 \mathrm{e}-05$ & $6.37 \mathrm{e}-05$ & $1.83 \mathrm{e}-05$ & $1.82 \mathrm{e}-05$ & $3.06 \mathrm{e}-05$ & $1.84 \mathrm{e}-05$ & $1.06 \mathrm{e}-05$ & $9.30 \mathrm{e}-06$ \\
\hline $54212 \mathrm{~A}$ & $1.05 \mathrm{e}-03$ & $2.32 \mathrm{e}-03$ & $1.78 \mathrm{e}-03$ & $2.07 \mathrm{e}-03$ & $9.61 \mathrm{e}-03$ & $3.10 \mathrm{e}-03$ & $7.74 \mathrm{e}-04$ & $7.05 \mathrm{e}-04$ \\
\hline $12305422 \mathrm{~B}$ & $8.70 \mathrm{e}-05$ & $1.30 \mathrm{e}-04$ & $3.37 \mathrm{e}-05$ & $4.85 \mathrm{e}-05$ & $3.48 \mathrm{e}-05$ & $4.25 \mathrm{e}-05$ & $1.76 \mathrm{e}-05$ & $2.14 \mathrm{e}-05$ \\
\hline $12305429 \mathrm{~A}$ & $1.40 \mathrm{e}-03$ & $4.39 \mathrm{e}-03$ & $1.12 \mathrm{e}-03$ & $1.65 \mathrm{e}-03$ & $6.39 \mathrm{e}-03$ & $2.59 \mathrm{e}-03$ & $4.62 \mathrm{e}-04$ & $2.57 \mathrm{e}-04$ \\
\hline $1230530-94 \mathrm{~A}$ & $2.20 \mathrm{e}-02$ & $2.65 e-02$ & $8.35 e-03$ & $8.40 \mathrm{e}-03$ & $9.13 \mathrm{e}-03$ & $7.42 \mathrm{e}-03$ & $5.00 \mathrm{e}-03$ & $3.68 \mathrm{e}-03$ \\
\hline $1230530-109 \mathrm{~A}$ & $3.13 e-03$ & $4.54 \mathrm{e}-03$ & $1.82 \mathrm{e}-03$ & $1.43 \mathrm{e}-03$ & $7.96 \mathrm{e}-03$ & $2.02 \mathrm{e}-03$ & $2.76 \mathrm{e}-04$ & $2.31 \mathrm{e}-04$ \\
\hline $1230530-89 \mathrm{~B}$ & $1.39 \mathrm{e}-02$ & $1.78 \mathrm{e}-02$ & $6.45 \mathrm{e}-03$ & $5.93 \mathrm{e}-03$ & $1.16 \mathrm{e}-02$ & $5.65 \mathrm{e}-03$ & $4.44 \mathrm{e}-03$ & $2.45 \mathrm{e}-03$ \\
\hline $1230530-89 \mathrm{~A}$ & $2.07 \mathrm{e}-02$ & $2.59 \mathrm{e}-02$ & $1.06 \mathrm{e}-02$ & $1.31 \mathrm{e}-02$ & $1.72 \mathrm{e}-02$ & $1.31 \mathrm{e}-02$ & $8.07 \mathrm{e}-03$ & $5.66 \mathrm{e}-03$ \\
\hline $1230530-86 a$ & $9.74 \mathrm{e}-03$ & $1.54 \mathrm{e}-02$ & $5.61 \mathrm{e}-03$ & $6.19 \mathrm{e}-03$ & $1.22 \mathrm{e}-02$ & $6.58 \mathrm{e}-03$ & $3.63 e-03$ & $2.36 \mathrm{e}-03$ \\
\hline $1230530-16 \mathrm{~A}$ & $4.25 \mathrm{e}-02$ & $4.92 \mathrm{e}-02$ & $4.16 \mathrm{e}-02$ & $4.48 \mathrm{e}-02$ & $5.06 \mathrm{e}-02$ & $4.39 \mathrm{e}-02$ & $5.11 \mathrm{e}-02$ & $4.13 \mathrm{e}-02$ \\
\hline
\end{tabular}

Table 2. Ideal separation factors for He and a second gas at two temperatures

Ideal Separation Factor for $\mathrm{He} / \mathrm{Gas}$

\begin{tabular}{|c|c|c|c|c|c|c|}
\hline \multirow[b]{2}{*}{ Tube } & \multicolumn{2}{|c|}{$\mathbf{O}_{2}$} & \multicolumn{2}{|c|}{$\mathrm{CO}_{2}$} & \multicolumn{2}{|c|}{$\mathrm{SF}_{6}$} \\
\hline & $23^{\circ} \mathrm{C}$ & $250^{\circ} \mathrm{C}$ & $23^{\circ} \mathrm{C}$ & $250^{\circ} \mathrm{C}$ & $23^{\circ} \mathrm{C}$ & $250^{\circ} \mathrm{C}$ \\
\hline $25227 \mathrm{a}$ & 2.70 & 4.87 & 0.71 & 3.08 & 10.20 & 41.16 \\
\hline $2528 \mathrm{~b}$ & 3.15 & 4.33 & 0.73 & 2.85 & 47.18 & 137.85 \\
\hline $5021 \mathrm{~b}$ & 2.22 & 3.89 & 0.32 & 2.51 & 35.68 & 134.86 \\
\hline $5022 \mathrm{a}$ & 1.40 & 3.12 & 0.25 & 1.98 & 13.18 & 43.36 \\
\hline $2527 \mathrm{~b}$ & 4.28 & 5.20 & 1.00 & 3.59 & 18.54 & 85.46 \\
\hline $2527 \mathrm{a}$ & 2.03 & 4.20 & 0.44 & 2.83 & 16.72 & 49.32 \\
\hline $5021 \mathrm{a}$ & 1.45 & 3.18 & 0.29 & 2.08 & 6.56 & 28.30 \\
\hline $25221 \mathrm{a}$ & 1.83 & 4.31 & 0.36 & 2.79 & 7.03 & 52.70 \\
\hline $25210 \mathrm{a}$ & 1.78 & 3.74 & 0.34 & 2.54 & 18.63 & 39.39 \\
\hline $2525 \mathrm{a}$ & 1.02 & 3.10 & 0.19 & 2.03 & 11.58 & 61.14 \\
\hline $108 \mathrm{~b}$ & 2.93 & 6.11 & 3.27 & 6.77 & 5.65 & 12.99 \\
\hline 60b & 2.64 & 2.82 & 2.73 & 3.32 & 4.28 & 5.74 \\
\hline $106 \mathrm{a}$ & 1.14 & 1.39 & 0.63 & 1.16 & 1.55 & 2.84 \\
\hline $108 \mathrm{a}$ & 2.53 & 4.17 & 1.79 & 4.08 & 3.92 & 10.47 \\
\hline $5426 a$ & 2.46 & 3.51 & 1.48 & 3.47 & 4.25 & 6.87 \\
\hline $54212 \mathrm{~A}$ & 0.59 & 1.12 & 0.11 & 0.75 & 1.36 & 3.28 \\
\hline $12305422 B$ & 2.58 & 2.68 & 2.50 & 3.06 & 4.94 & 6.06 \\
\hline 12305429A & 1.25 & 2.66 & 0.22 & 1.69 & 3.03 & 17.06 \\
\hline $1230530-94 \mathrm{~A}$ & 2.64 & 3.15 & 2.41 & 3.57 & 4.40 & 7.21 \\
\hline 1230530-109A & 1.72 & 3.18 & 0.39 & 2.25 & 11.37 & 19.66 \\
\hline 1230530-89B & 2.15 & 3.00 & 1.20 & 3.15 & 3.13 & 7.28 \\
\hline $1230530-89 \mathrm{~A}$ & 1.95 & 1.98 & 1.20 & 1.98 & 2.56 & 4.58 \\
\hline $1230530-86 a$ & 1.74 & 2.49 & 0.80 & 2.34 & 2.69 & 6.54 \\
\hline $1230530-16 \mathrm{~A}$ & 1.02 & 1.10 & 0.84 & 1.12 & 0.83 & 1.19 \\
\hline
\end{tabular}


Table 3 Pore diameter of membrane calculated from measured separation factors of helium and each gas and the Hard Sphere Model (angstroms)

\begin{tabular}{lrrr} 
Tube & $\mathbf{C O}_{\mathbf{2}}$ & $\mathbf{S F}_{\mathbf{6}}$ & $\mathbf{O}_{\mathbf{2}}$ \\
\hline $25227 \mathrm{a}$ & 5.50 & 6.69 & 5.19 \\
$2528 \mathrm{~b}$ & 5.74 & 6.34 & 6.34 \\
$5021 \mathrm{~b}$ & 5.04 & 6.24 & 5.70 \\
$5022 \mathrm{a}$ & 5.18 & 6.82 & 5.49 \\
$2527 \mathrm{~b}$ & 5.60 & 6.30 & 6.28 \\
$2527 \mathrm{a}$ & 5.13 & 6.83 & 5.14 \\
$5021 \mathrm{a}$ & 5.27 & 6.87 & 5.50 \\
$25221 \mathrm{a}$ & 5.00 & 6.25 & 4.88 \\
$25210 \mathrm{a}$ & 5.08 & 7.36 & 5.29 \\
$2525 \mathrm{a}$ & 4.93 & 6.36 & 4.87 \\
$108 \mathrm{~b}$ & 5.70 & 8.95 & 4.69 \\
$60 \mathrm{~b}$ & 13.66 & 30.71 & 34.51 \\
$106 \mathrm{a}$ & -46.89 & 273.62 & -3.25 \\
$108 \mathrm{a}$ & 6.29 & 9.00 & 5.73 \\
$5426 \mathrm{a}$ & 6.57 & 15.76 & 7.16 \\
$54212 \mathrm{~A}$ & 6.97 & 20.45 & -24.93 \\
$12305422 \mathrm{~B}$ & 15.75 & 36.74 & -395.96 \\
$12305429 \mathrm{~A}$ & 5.35 & 6.98 & 6.05 \\
$1230530-94 \mathrm{~A}$ & 9.04 & 14.85 & 11.13 \\
$1230530-109 \mathrm{~A}$ & 5.45 & 8.84 & 6.09 \\
$1230530-89 \mathrm{~B}$ & 6.47 & 10.99 & 8.68 \\
$1230530-89 \mathrm{~A}$ & 17.94 & 22.48 & -5.28 \\
$1230530-86 \mathrm{a}$ & 6.84 & 11.25 & 11.04 \\
$1230530-16 \mathrm{~A}$ & -4.58 & -3.69 & -0.26
\end{tabular}




\section{Conclusions}

Much of the work during the past year has been directed toward increasing membrane permeance, achieving repeatability with defect-free membranes, and using materials and techniques that can be approved by the DOE review process and manufactured on a large scale. Significant progress has been made in all these areas. We are significantly expanding our understanding of gas transport in inorganic membranes. Recent results have shown ideal separation factors for helium over sulfur hexafluoride of more than 45 at $23^{\circ} \mathrm{C}$ and more than 140 at $250^{\circ} \mathrm{C}$. Also, it has been observed that the permeance of helium increases significantly with increasing temperature. As a result, even higher permeance and separation factors should be attainable at higher operating temperatures.

Future work will include testing some of the new membranes that have shown high ideal separation factors for helium over sulfur hexafluoride with hydrogen to confirm that our results also apply to hydrogen. Also, efforts will be made to test the best membranes at temperatures approaching $600^{\circ} \mathrm{C}$ to empirically determine how much the permeance and separation factors increase with increasing temperature. Finally, the membranes need to be evaluated under simulated coal-derived synthesis gas conditions to determine their actual separation performance and long-term stability.

\section{Acknowledgements}

This research was sponsored by the U.S. Department of Energy, Office of Fossil Energy Advanced Research Materials Program, DOE/FE AA1510100, and Work Breakdown Structure Element IMTL-3 (B). Oak Ridge National Laboratory is managed by UT Battelle, LLC, for the U. S. Department of Energy under contract DEAC05-00OR22725. Accordingly, the U.S. Government retains a nonexclusive, royalty-free license to publish or reproduce the published form of this contribution, or allow others to do so, for U.S. Government purposes.

\section{References}

1. D. E. Fain and G. E. Roettger, Effects of Leaks on Gas Separation Performance of A Nano Pore Size Membranes, K/TSO-24, Lockheed Martin Energy Systems, Inc. Oak Ridge, K-25 Site, Oak Ridge, Tennessee, October 1996.

2. D. E. Fain and G. E. Roettger, "Development of Ceramic Membranes for Gas Separation," Proceedings for the Fourth Annual Conference on Fossil Energy Materials, Oak Ridge, Tennessee, May 15-17, 1990, pp. 183-94.

3. D. E. Fain, G. E. Roettger, and D. E. White, "Development of Ceramic Membranes for High Temperature Hydrogen Separation," Proceedings for the Fifth Annual Conference on Fossil Energy Materials, Oak Ridge, Tennessee, May 14-16, 1991, pp. 55-64. 